\title{
Occupational Mobility and Lifetime Earnings
}

\author{
Yongseok Shin and C.Y. Kelvin Yuen
}

People's occupations have a significant amount of information about their wages. However, because people-especially young workers-go through multiple occupations and employment statuses during their working lives, we find that their occupations at a young age do not predict their lifetime earnings well. When educational attainment and gender are considered, we find that across education-gender groups the differences in lifetime earnings are even larger than the differences in average occupational wages: Workers in high-wage education-gender groups (men with college degrees, for example) work more (at the extensive margin) and are more likely to have higher-paying occupations. (JEL E24, J24, $\mathrm{J} 31, \mathrm{~J} 62)$

Federal Reserve Bank of St. Louis Review, Third Quarter 2019, 101(3), pp. 231-44. https://doi.org/10.20955/r.101.231-44

\section{INTRODUCTION}

Occupations signify people's economic standing: One can safely assume that doctors and lawyers are better off than cooks and janitors. In this article, we ask how much information on people's labor market outcomes is encapsulated in their occupations. We first consider how much of overall wage inequality can be accounted for by the differences in average wages of occupations (between-occupation inequality). We then examine how informative a person's occupation at a young age (i.e., 25 years of age) is about that person's lifetime earnings. Because the calculation of lifetime earnings takes into account the fact that people go through multiple occupations and employment statuses, we will look for patterns of mobility across occupations. Finally, we divide the data by education and gender groups to see how average wages and lifetime earnings vary across occupations within and across the groups.

Our first finding is that occupations provide a significant amount of information on workers' wages in the cross section-average wages of occupations vary significantly: Even when we divide occupations into only 22 occupation categories, the highest average wage

Yongseok Shin is a professor of economics at Washington University in St. Louis and a research fellow at the Federal Reserve Bank of St. Louis. C.Y. Kelvin Yuen is a Ph.D. candidate in economics at Washington University in St. Louis.

○ 2019, Federal Reserve Bank of St. Louis. The views expressed in this article are those of the author(s) and do not necessarily reflect the views of the Federal Reserve System, the Board of Governors, or the regional Federal Reserve Banks. Articles may be reprinted, reproduced, published, distributed, displayed, and transmitted in their entirety if copyright notice, author name(s), and full citation are included. Abstracts, synopses, and other derivative works may be made only with prior written permission of the Federal Reserve Bank of St. Louis. 
(legal) is nearly three times the lowest average wage (food preparation and serving). However, because workers go through multiple occupations and employment statuses during their working lives, especially when young, we find that their occupations at a young age do not predict their lifetime earnings well.

Our second finding is about the earnings gaps between education-gender groups. Even within the same occupation category, some groups (for example, men with college degrees) earn more than others. When we compute between-group differences in lifetime earnings, conditioning on occupation category at age 25 , the fact that people go through multiple occupation categories and employment statuses amplifies the between-group wage differences within an occupation category. This amplification occurs because workers in high-wage education-gender groups work more (at the extensive margin) and are more likely to remain in higher-paying occupation categories.

In recent years, many macro-labor models of tasks and occupations have equated workers' occupations with their skill levels (see the review of Acemoglu and Autor, 2011). Once we factor in occupational mobility, however, our analysis suggests that the link between occupation and skill may be weaker than has often been assumed.

Our finding on inequality in wage and lifetime earnings between education-gender groups relates to studies showing that occupation-specific human capital and tenure explains wage growth and inequality (see the review of Sanders and Taber, 2012).

\section{DATA}

To compute wages and occupational mobility, we use the Current Population Survey (CPS). To be more specific, we use monthly CPS Outgoing Rotation Groups (ORG) data, which have a rotating panel structure: Each household participates in four consecutive monthly interviews, is dropped from the sample for the following eight months, and finally participates in another four consecutive monthly interviews. This structure allows us to match individuals from one month to another using their race, sex, and age (Nekarda, 2009). We restrict our sample to those 22 to 55 years of age and look at the 15 -year period 2003-17. 1 In total, we have 7,696,838 observations in our ORG sample. In the computations, individuals are weighted by their composited final weight for the CPS.

The CPS records the occupation of an employed individual and the most-recent occupation of an unemployed individual. For those out of the labor force, there is no occupation information. To have enough observations for each occupation, we divide the 571 occupations in our sample into 22 occupation categories using the Detailed Occupation Recodes in the CPS, excluding the Armed Forces.

To compute the average wage of each of the 22 occupation categories, we use the microdata from the CPS Annual Social and Economic Supplement, which is conducted every March and asks more-detailed questions about each individual's labor income. We again restrict our sample to those who are 22 to 55 years of age and the period 2003-17. We have 1,026,605 observations. Each average hourly wage is calculated as the total annual wage and salary earnings divided by the product of the number of weeks worked and the usual hours worked per

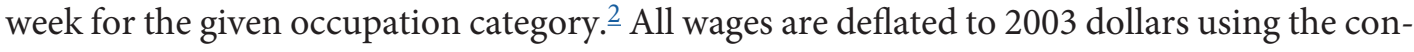


sumer price index from the Bureau of Labor Statistics. For each year, we trim wages at the 0.1 and 99.9 percentiles to exclude outliers.

\section{BETWEEN-OCCUPATION INEQUALITY IN WAGES AND LIFETIME EARNINGS}

To give an overview of our analysis, in Figure 1 we start with three Lorenz curves. A Lorenz curve is a visual representation of inequality. On the horizontal axis, we order people in the economy by their wages, from 0 to 100 percentiles. On the vertical axis, we plot the fraction of total wages that belongs to the people to the left of a given percentile. If everyone has the same wage, then the Lorenz curve will be the 45-degree line: $x$ percent of the population will account for exactly $x$ percent of total wages-perfect equality. The farther away from the 45-degree line a Lorenz curve is, the more unequal the wage distribution is.

We first construct a Lorenz curve using the wage distribution of the entire sample, which is the purple curve labeled "Cross-sectional" in Figure 1. This curve is far from the 45-degree line, showing substantial wage inequality in the economy. One measure of the degree of inequality is the Gini coefficient, which is the area between a Lorenz curve and the 45-degree line divided by the area of the triangle of which the hypotenuse is the 45 -degree line. Thus, a Gini coefficient ranges from 0 (no inequality) to 1 (the extreme case where all wages of the entire economy go to one person). The Gini coefficient of the wage distribution is $0.38 . \underline{3}$

To show how much of this inequality is attributable to wage differences across occupation categories, we make the (very strong) assumption that everyone in the same occupation category has the same wage. Now all remaining wage inequality is solely due to wage differences across occupation categories. The orange curve labeled "Hourly Wage (pooled)" is the resulting Lorenz curve. It is closer to the 45-degree line, as it should be, because we assumed no wage inequality within any given occupation category. What is remarkable is that this curve sits almost halfway between the cross-sectional Lorenz curve and the 45-degree line. In other words, between-occupation-category wage differences account for as much as half of the Gini coefficient of the actual wage distribution ( 0.19 of 0.38 ) - a very large fraction considering we have only 22 occupation categories and do not control for conventional explanatory variables of wages, such as education, age, gender, and race. This exercise confirms that occupations indeed encapsulate a significant amount of information on people's economic standing.

However, people's wages at a given point in time are a very partial measure of their lifetime labor income, which is what matters the most for their lifetime economic well-being. We construct the present discounted value of lifetime earnings at 25 years of age (PDV at 25) for each occupation category, using an annual interest rate of 2 percent. We now assume that everyone of the same age and in the same occupation category earns the same wage. Instead of assuming that people stay in the same occupation category throughout their working lives, we calculate from the data the probability of changing occupation categories or even becoming unemployed. (See the appendix for the details.) The yellow curve labeled "PDV (age specific)" is the resulting Lorenz curve and is nearly indistinguishable from the 45-degree line. Thus, we find that PDV at 25 varies very little across occupation categories. 
Figure 1

Lorenz Curves for Wages and PDV at 25

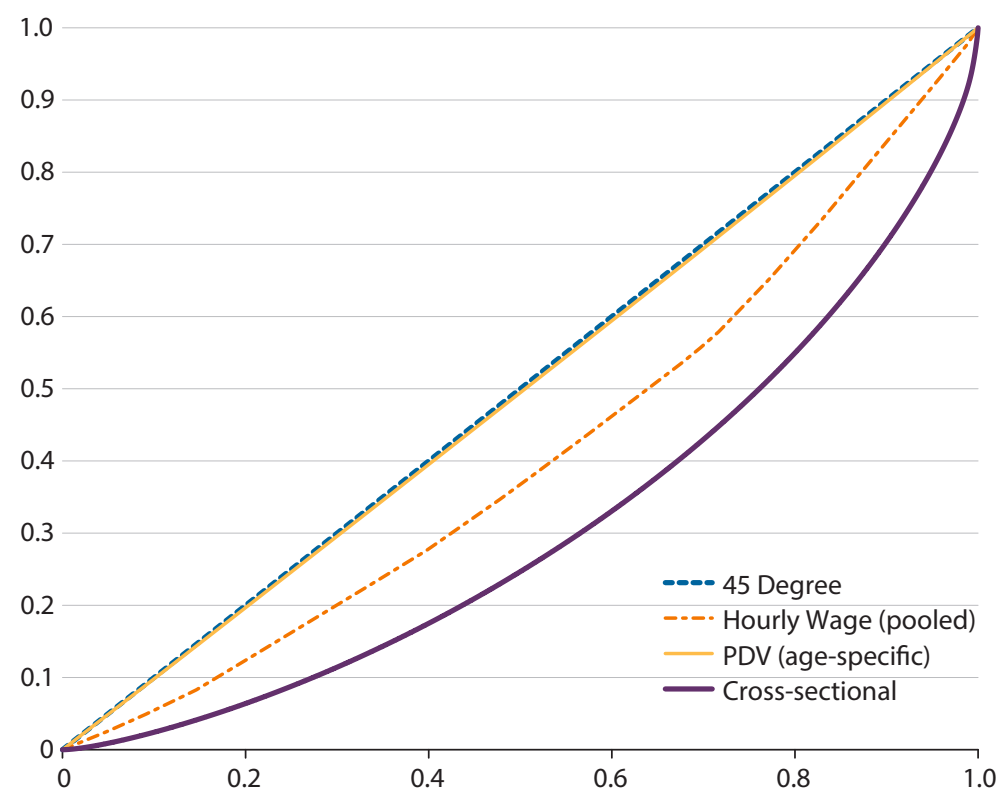

NOTE: This figure plots Lorenz curves for the hourly-wage distribution ("Cross-sectional"), the wage distribution assuming everyone with the same occupation earns the same wage ("Hourly Wage (pooled)"), and the distribution of the PDV at 25 by occupation group ("PDV (age-specific)"). The horizontal axis is the cumulative percentage of workers in the economy, ordered by their wages or PDV at 25, and the vertical axis is the cumulative percentage of their wages. See the data section for details about the data processing and the appendix for the derivation of PDV at 25.

SOURCE: Authors' calculations using the CPS Annual Social and Economic Supplement microdata for the period 2003-17.

There are two reasons why PDV at 25 is much more equal across occupation categories than wages are. First, differences in wages across occupations "fan out" over the life cycle: That is, the difference between high-paying occupations and low-paying occupations is larger for older workers than for young workers. Accounting for age and also discounting future earnings make PDV at 25 more equal across occupation categories. However, what is much more important is occupational mobility. People switch occupations over the course of their working lives and especially frequently when they are young: A 25 year old on average stays with one occupation for a mere eight months (before either changing occupations or dropping out of labor force); and even for a 45 year old, the expected duration is only slightly more than one year. As a result, people's occupation categories at age 25 have very limited information on their lifetime earnings, as illustrated by the Lorenz curve that collapses onto the 45-degree line. For the very same reasons, people's occupations at later ages do have more information on their remaining lifetime earnings; but even for 45 year olds, the PDV at 45 Lorenz curve is closer to the 45-degree line than to the hourly-wage Lorenz curve.

The analysis above looked at wages and labor supply at only the extensive margin (employment status). We also conducted a similar exercise using actual earnings (wage times hours 


\section{Table 1}

\section{Comparison of Occupations}

\begin{tabular}{|c|c|c|c|c|c|c|c|c|c|}
\hline Occupation category & $\begin{array}{c}\text { PDV at } 25 \\
\text { (norm.) }\end{array}$ & $\begin{array}{c}\text { Wage rate } \\
(2003 \$)\end{array}$ & $\begin{array}{c}\text { EU } \\
\text { Separation } \\
(\%)\end{array}$ & $\begin{array}{c}\text { EU+EN } \\
\text { Separation } \\
(\%)\end{array}$ & $\begin{array}{c}\text { Job } \\
\text { finding (\%) }\end{array}$ & $\begin{array}{l}\text { UE exp. } \\
\text { wage } \\
(2003 \$)\end{array}$ & $\begin{array}{c}\text { Job } \\
\text { switching } \\
(\%)\end{array}$ & $\begin{array}{c}\text { Switching } \\
\text { exp. wage } \\
(2003 \$)\end{array}$ & $\begin{array}{c}\text { Gross flows } \\
\text { (\%) }\end{array}$ \\
\hline Architecture and Engineering & 1.041 & 28.50 & 0.55 & 1.31 & 21.44 & 19.53 & 1.39 & 22.23 & 10.89 \\
\hline Computer and Math & 1.036 & 29.05 & 0.58 & 1.50 & 19.63 & 19.76 & 1.65 & 22.53 & 11.51 \\
\hline Healthcare Practitioner & 1.023 & 26.87 & 0.41 & 1.68 & 27.97 & 19.78 & 1.58 & 21.48 & 9.14 \\
\hline Legal & 1.022 & 36.10 & 0.43 & 1.62 & 23.60 & 20.45 & 1.70 & 24.02 & 9.21 \\
\hline Business and Financial & 1.022 & 24.73 & 0.66 & 1.82 & 21.67 & 17.48 & 1.68 & 19.26 & 13.78 \\
\hline Life, physical, and Social Science & 1.020 & 24.83 & 0.68 & 1.88 & 23.26 & 19.33 & 1.64 & 20.90 & 12.84 \\
\hline Management & 1.013 & 28.53 & 0.58 & 1.67 & 21.17 & 17.04 & 1.45 & 19.64 & 11.68 \\
\hline Arts, Design, and Entertainment & 1.009 & 20.83 & 1.60 & 4.06 & 27.21 & 17.17 & 2.43 & 17.47 & 17.73 \\
\hline Community and Social Service & 1.006 & 16.47 & 0.58 & 2.11 & 21.83 & 16.20 & 1.83 & 16.97 & 12.63 \\
\hline Protective Service & 1.004 & 19.26 & 0.74 & 2.09 & 21.05 & 14.72 & 1.46 & 15.71 & 10.47 \\
\hline Installation, Maintenance, and Repair & 1.001 & 17.33 & 1.13 & 2.40 & 22.43 & 14.28 & 1.64 & 16.37 & 13.27 \\
\hline Education, Training, and Library & 1.000 & 17.65 & 0.90 & 3.11 & 34.54 & 16.23 & 1.72 & 16.39 & 11.55 \\
\hline Sales & 0.997 & 18.07 & 1.08 & 3.15 & 20.00 & 13.88 & 2.05 & 14.69 & 15.33 \\
\hline Office and Administrative Support & 0.996 & 14.36 & 0.99 & 2.94 & 19.04 & 14.38 & 1.72 & 15.14 & 14.80 \\
\hline Production & 0.993 & 14.53 & 1.65 & 3.41 & 21.65 & 12.34 & 1.68 & 12.67 & 15.54 \\
\hline Construction and Extraction & 0.992 & 16.54 & 3.42 & 5.56 & 29.58 & 13.79 & 2.46 & 13.98 & 18.84 \\
\hline Healthcare Support & 0.990 & 11.52 & 1.21 & 3.75 & 22.97 & 12.85 & 1.95 & 13.11 & 17.69 \\
\hline Transportation and Material Moving & 0.989 & 14.27 & 1.94 & 4.07 & 23.53 & 12.08 & 2.20 & 12.66 & 17.69 \\
\hline Personal Care and Service & 0.985 & 11.42 & 1.47 & 5.30 & 23.16 & 12.26 & 2.29 & 12.60 & 19.92 \\
\hline Building and Grounds Cleaning & 0.983 & 10.60 & 2.24 & 5.63 & 22.92 & 10.66 & 2.35 & 10.71 & 20.87 \\
\hline Food Preparation and Serving & 0.983 & 9.68 & 1.86 & 4.86 & 23.13 & 11.57 & 2.73 & 11.95 & 18.25 \\
\hline Farming, Fishing, and Forestry & 0.981 & 10.20 & 3.79 & 7.19 & 30.05 & 10.98 & 2.79 & 11.70 & 25.00 \\
\hline Correlation with PDV & 1.00 & 0.91 & -0.70 & -0.83 & -0.21 & 0.95 & -0.71 & 0.96 & -0.78 \\
\hline
\end{tabular}

worked) data. There is more inequality in earnings in the cross section (a Gini of 0.43 , compared with 0.38 for wages), but the analysis yields fairly similar results, suggesting that the intensive margin of the labor supply plays only a minor role in these calculations.

\section{HOW DO OCCUPATIONS DIFFER?}

The exercises so far show how much information people's occupation categories provide about their wages and lifetime earnings, but are silent about how occupations differ from one another, for example in terms of wages or mobility. We now make such comparisons.

As shown in the first column of Table 1, we have 22 occupation categories. They are sorted by PDV at 25 normalized by their averages, from highest to lowest (column "PDV at 
25 (norm.)"). As discussed above, there is very little difference across occupation categories: The difference between the highest (architecture and engineering) and the lowest PDV at 25 (farming, fishing and forestry) is only 6 percent.

In the next column ("Wage rate"), we show the average wage of each occupation, which we used to construct the "Hourly Wage" Lorenz curve in Figure 1. Two facts stand out. First, the average wages of the occupation categories vary greatly, unlike PDV at 25: The highest average wage (legal) is nearly four times as high as the lowest (food preparation and serving). Second, in spite of this stark difference, average wages are very strongly correlated with PDV at 25 (correlation coefficient of 0.91). In other words, ranking occupations either by wages or by PDV at 25-the idea being that people want higher average wages and lifetime earningsprovides very similar rankings.

In the next five columns, we consider the notions of job security and occupational mobility. We first look at job separation rates by occupation category, defined as the rate at which a worker in a given occupation category becomes unemployed in the next month (column "EU Separation"; EU stands for employment to unemployment). For the majority of occupations, it is less than 1 percent, but there are outliers. It is nearly 4 percent for the farming, fishing, and forestry occupation category, likely reflecting the seasonal nature of employment in this category. The EU separation rate is also high for the construction and extraction occupation category ( 3.42 percent), partly because of the massive destruction of such jobs during the Great Recession. The EU separation rates are negatively correlated with PDV at 25 (correlation coefficient of -0.70), implying that occupation categories with high average lifetime earnings (and high average wages) lose fewer workers to unemployment. Since people want higher earnings and not to be unemployed, the rankings of occupation categories by PDV at 25 and by the inverse of the EU separation rates broadly coincide.

We also consider a broader notion of job separation, by calculating the rate at which a worker in a given occupation category becomes unemployed or leaves the labor force (nonparticipation) in the next month (column "EU+EN Separation"; EN stands for employment to nonparticipation). While the majority of EU transitions are involuntary, it is difficult to figure out which EN transitions are voluntary (for example, retirement) or involuntary. The broadly defined EU+EN separation rates vary across occupation categories more than the more conventionally defined (EU) job separation rates do, and they are even more negatively correlated with PDV at 25 (correlation coefficient of -0.83 ). $\underline{6}$

The next column ("Job finding") shows the job finding rates of unemployed workers by their previous occupation category. The job finding rate is the rate at which unemployed workers become employed in any occupation category in the next month. The job finding rates by previous occupation category vary quite a bit-for example, those who become unemployed from the education, training, and library occupation category have about a 35 percent chance of finding another job in a month, while those in the office and administrative support occupation category have about a 19 percent chance. However, the job finding rates do not show a clear pattern, as they are not strongly correlated with PDV at 25 (correlation coefficient of -0.21). What is interesting is that the correlation is negative: If a worker in a higher-paying occupation category becomes unemployed, that worker is expected to stay unemployed a little longer than those in lower-paying occupation categories. 
Getting out of unemployment is a good thing, but it also matters what kind of job one lands in out of unemployment. We compute the wage an unemployed worker could expect when finding a new job, by the worker's previous occupation category ("UE exp. wage" column). Each expected wage is computed by first multiplying the chance of getting employed in a particular occupation out of unemployment by the average wage of that occupation (considering the worker's age), and then adding these products across all 22 occupation categories. Expected wages by previous occupation category are very strongly correlated with PDV at 25 (correlation coefficient of 0.95 ) and with average wages across occupation categories. The reason is fairly simple: Unemployed workers tend to return to their previous occupation category: 48 percent of those moving out of unemployment return to their previous occupation category, even though there are 22 possible categories.

We now consider occupational mobility that does not involve a spell of unemployment or nonparticipation. The first variable we construct is a job-switching rate (column "Job switching"). This is the rate at which employed workers in a given occupation category switch employers in the next month (known as job-to-job transition), regardless of whether they switch occupation categories. The job-switching rate is strongly negatively correlated with PDV at 25 (correlation coefficient of -0.71) and with average wages across occupation categories: Workers in high-paying occupation categories are less likely to switch jobs.

We also look at the expected wages of those who make job-to-job transitions (column "Switching exp. wage"). As for the expected wages out of unemployment above (UE exp. wage), this is computed by first multiplying the probability of getting employed in a particular occupation category by the average wage of the new occupation category (considering the worker's age), and then adding these products across all 22 occupation categories. The expected wages for job switchers are closely correlated with PDV at 25 (correlation coefficient of 0.96) and with average wages across occupation categories, again primarily because even job switchers tend to remain in the same occupation category: 54 percent of job switchers do not change occupation categories.

Finally, we construct another measure of occupational mobility that captures the flow of workers into and out of each occupation category (column "Gross flows"). Specifically, the monthly gross flow rate of each occupation category $o$ is the sum of the outflow (the number of workers who are employed in occupation category $o$ in month $m$ but not in month $m+1$ ) and the inflow (the number of workers who are employed in occupation category $o$ in month $m+1$ but not in $m$ ) divided by the average number of workers employed in occupation category $o$ in months $m$ and $m+1$. A high gross flow rate implies a higher rate of turnover, or "churning," for the occupation category. $\underline{\underline{Z}}$ We note that, first, there are large variations in the gross flow rates across occupation categories: from lows of about 9 percent each for the healthcare practitioner and legal occupation categories to a high of 25 percent for the farming, fishing, and forestry occupation category. By comparison, the net flow rates across occupation categories have a standard deviation of 4.2 percent over the sample period: In other words, even the smallest gross flow rate among occupation categories is more than twice the standard deviation of net changes in occupational employment. Second, the gross flow rates are strongly negatively correlated with PDV at 25 (correlation coefficient of -0.78) and with average wages across occupation categories: High-paying occupations have lower turnover rates. 
The results in Table 1 are as follow. First, starting one's career (at age 25) in an occupation category with a high average wage promises a high PDV at 25, but the differences in PDV at 25 across occupation categories is tiny relative to the differences in average wages across them. Second, high-paying occupation categories (either in terms of PDV at 25 or average wages) have less turnover (churning), as measured by the separation rates (the fraction becoming unemployed and/or out of the labor force in a month) and the gross flow rates. The job finding rates for those who become unemployed from high-paying occupation categories are also somewhat lower as well, although this pattern is not very clear (correlation coefficient of -0.21).

What can we make out of these findings? For one, we can safely reject any notion that high wages of an occupation compensate for the risk of becoming unemployed. If that were true, one should find a positive relationship between wages and separation rates across occupation categories. For another, the negative relationship between wages and gross flows suggests that high wages of an occupation reflect special skills and occupation-specific human capital that take time to develop. The fact that the healthcare practitioner, legal, and architecture and engineering occupation categories have the lowest gross flow rates supports this idea. We explore this subject in our ongoing research projects.

\section{WAGES AND LIFETIME EARNINGS ACROSS OCCUPATION CATEGORIES: THE ROLE OF EDUCATION AND GENDER}

In our analysis so far, we differentiated people by only their age and occupation category. The more traditional approach in labor economics is to group people by their educational attainment and gender. One natural question is whether a person's occupation has more or less information than his or her demographic characteristics such as education and gender. To answer this question, we break down our sample into two educational groups (bachelor's degree or more vs. less than a bachelor's degree, including those with some college education) for each gender.

Figure 2 plots in log scales average wages of the 22 occupation categories (sorted by the PDV at 25 variable in Table 1, from lowest to highest) for each of the four education-gender groups. We can readily confirm two well-known facts in labor economics holding across all occupations. First, all occupations have a college premium: The average wages of those with a bachelor's degree or more are higher than the average wages of those with less education, regardless of gender. - Second, once educational attainment is controlled for, all occupation categories have a gender gap: Men have higher average wages than women of the same educational group in all occupations. $\stackrel{9}{ }$

Closer to the theme of this article, we note the sizable differences in average wages across occupation categories within each education-gender group. We also note that the rankings of the occupation categories by average wages are roughly the same across all four educationgender groups. We confirm that occupations contain a significant amount of information on people's economic standing, even after accounting for the roles of education and gender.

We also compute the PDV at 25 by education and gender. We use age-specific average wages and transition probabilities of each education-gender group to construct the PDV at 25. 
Figure 2

\section{Average Wages of Occupations, by Education and Gender}

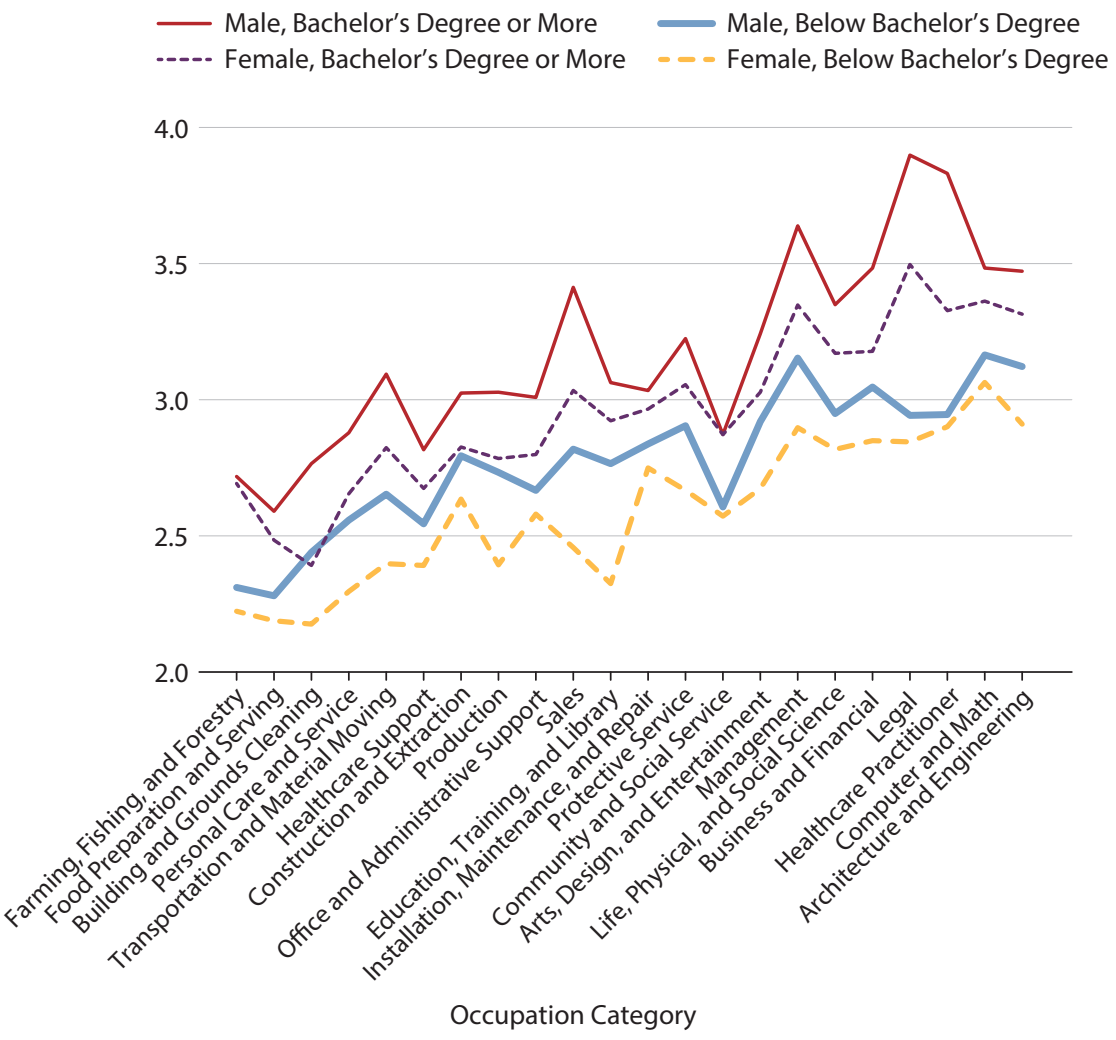

NOTE: This figure plots in logs scales the average hourly wages of occupations, from lowest to highest, by education and gender.

SOURCE: Authors' calculations using the CPS Annual Social and Economic Supplement microdata for the period 2003-17.

As already noted, there is very little difference in PDV at 25 across occupations in the overall sample (see column "PDV at 25 (norm.)" in Table 1). As shown in Figure 3, this result holds within each education-gender group: All four lines are essentially flat. For all educationgender groups, the ranking of the occupation categories (horizontal axis, from lowest to highest) more or less coincides with the ranking of PDV at 25 for the overall sample .

What is striking is the large gaps among the four education-gender groups. The average wage differences across occupation categories within an education-gender group do not translate into commensurate differences in PDV at 25, because people keep changing occupation categories. The wage differences across education-gender groups, however, persist even in the PDV at 25 calculations because the workers in our sample rarely change their education status, let alone gender. $\underline{10}$

Furthermore, the differences (in logs) in PDV at 25 across education-gender groups (see Figure 3 ) are bigger than the differences in average wages across the groups (see Figure 2). 
Figure 3

\section{Average PDV at 25 of Occupations, by Education and Gender}

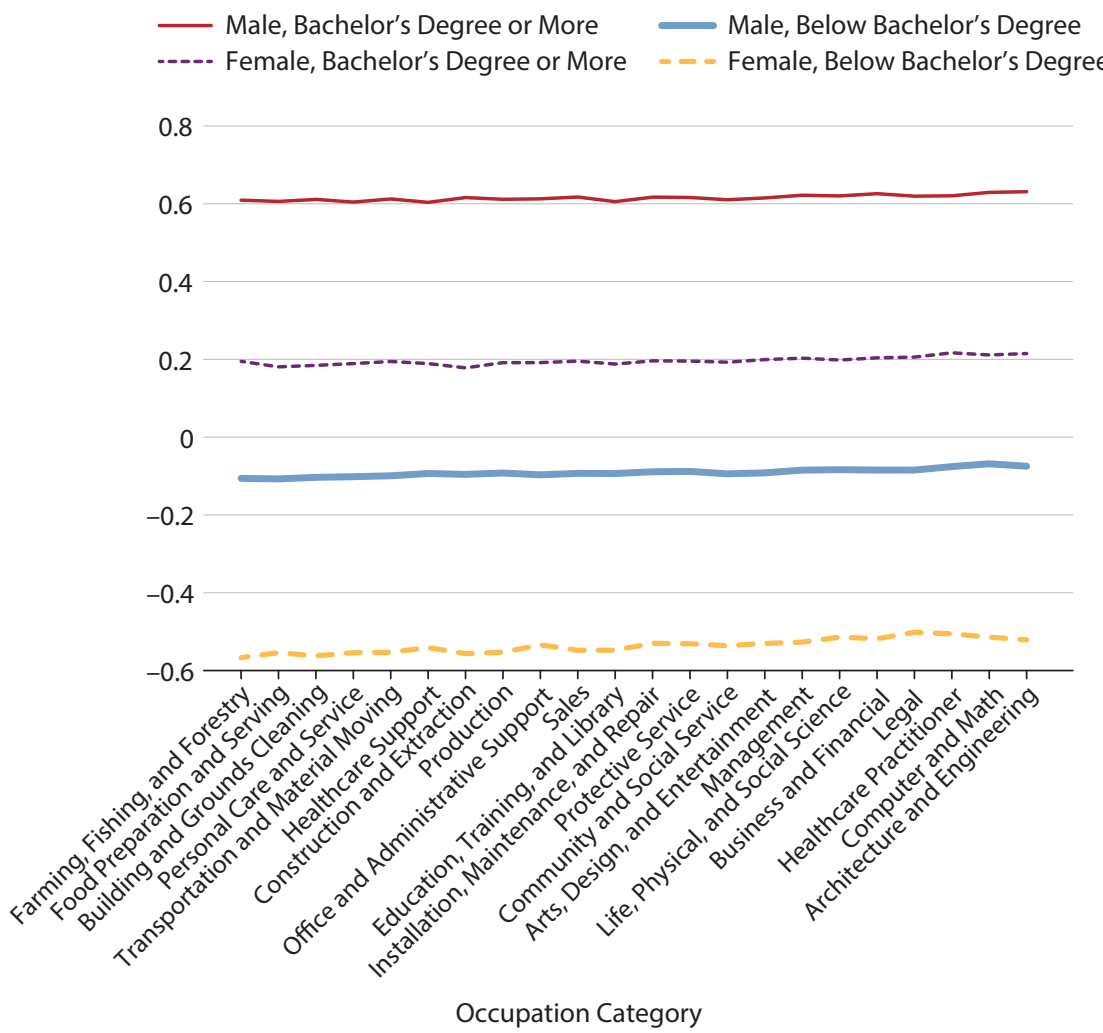

NOTE: This figure plots in log scales the PDV at 25 of occupations by education and gender. All PDV at 25 are normalized by their averages.

SOURCE: Authors' calculations using the CPS Outgoing Rotation Groups and Annual Social and Economic Supplement microdata for the period 2003-17.

There are two reasons. First, some groups work more than others. Between 25 and 55 years of age, men with a bachelor's degree or more on average are employed 91.6 percent of all months. The figures are 80.5 percent for women with a bachelor's degree or more, 80.2 percent for men with less education, and 66.2 percent for women with less education. In other words, the groups with higher wages work more (to be precise, are employed for a larger fraction of their prime working years), amplifying the differences in wages across the four educationgender groups. Second, those in the education-gender groups with higher wages across occupation categories are more likely to work in high-wage occupation categories than low-wage occupation categories over the course of their working lives. The composition of occupations within the education-gender groups also contributes to the differences in PDV at 25 across groups being bigger than the between-group differences in average occupational wages. 


\section{CONCLUDING REMARKS}

Occupations do encapsulate a significant amount of information about people's economic standing. However, because people change their occupations and even become unemployed over the course of their working lives, people's occupations at a young age are not very informative about their lifetime earnings. Calculation of the PDV at 25 necessitates estimation of the transition probabilities of moving from one employment status to another and also from one occupation category to another. Our analysis shows that high-paying occupation categories have lower turnover rates: Workers move into and out of high-paying occupation categories at a slower pace, be it employment-to-unemployment or job-to-job transitions.

The lifetime earnings results suggest that one should be careful about readily equating workers' occupations with their skill levels, a common practice in a large macro-labor literature (see Lee and Shin, 2017, and the references therein).

Conditioning on education and gender, the rankings of occupation categories by average wages and by PDV at 25 remain the same. The lifetime earnings differences across educationgender groups are larger than the differences in average wages across occupation categories because high-wage groups work more (at the extensive margin) and also are more likely to work in high-wage occupation categories.

This article leaves out some of our related findings. One is the patterns in worker flows across employment statuses and occupation categories separately computed by gender and education, which we used in our construction of Figure 3. Another is the pattern of worker flows during booms and recessions. $\underline{11}$ These deserve more thorough analyses and are left for future research. 


\section{APPENDIX}

\section{Computing the Present Discounted Value of Lifetime Earnings}

There are 22 occupations. Although we know the previous occupation categories of those unemployed, we do not know the previous occupation categories of those out of the labor force. In a given month, there are 45 possible states: employed in occupation categories 1 through 22 ( $E 1$ to $E 22$ ), unemployed from previous occupation categories 1 through 22 (O1 to $\mathrm{O} 22$ ), and out of the labor force ( $N$ for nonparticipation). For each occupation category $o$ and age $a$, we denote the value of being employed by $V_{a}^{E o}$, the value of being unemployed by $V_{a}^{U o}$, and the value of being out of the labor force by $V_{a}^{N}$. We can construct the 45-by-45 transition matrix $P_{a}=\left\{p_{a}^{i, j}\right\}$, where $P_{a}^{i, j}$ is the monthly transition probability from state $i$ to state $j$ at age $a$. The value of any state $i$ can be defined recursively as

$$
V_{a}^{i}=w_{a}^{i}+\beta \sum_{j=1}^{45} p_{a}^{i, j} V_{a+1}^{j}
$$

where $\beta$ is a discount factor and $w_{a}^{i}$ is the real hourly wage of the current occupation category (in 2003 dollars) at age $a$ if employed, 40 percent of the real hourly wage of the previous occupation category at age $a$ if unemployed, and zero if out of the labor force.

In matrix form, this system of equations can be written as

$$
V_{a}=w_{a}+\beta P_{a} V_{a+1}
$$

where $V_{a}=\left(V_{a}^{E 1}, V_{a}^{E 2}, \ldots, V_{a}^{N}\right)^{T}$ and $w_{a}=\left(w_{a}^{E 1}, w_{a}^{E 2}, \ldots, w_{a}^{N}\right)^{T}$. The terminal condition at $a=A+1$ is set to $V_{A+1}^{i}=0$ for all $i$. Forward iteration gives us

$$
\begin{aligned}
V_{a} & =w_{a}+\beta P_{a} w_{a+1}+\beta^{2} P_{a} P_{a+1} V_{a+2} \\
& =w_{a}+\beta P_{a} w_{a+1}+\beta^{2} P_{a} P_{a+1} w_{a+2}+\ldots+\beta^{A-a}\left(P_{a} P_{a+1} \cdots P_{A-1}\right) w_{A} .
\end{aligned}
$$

The expected value of occupation category $o$ in the first month of age 25 is $V_{25 m 1}^{E o}$ with $A=55 \times 12$ months. The monthly discount factor $\beta$ is assumed to be 0.99835 , which is equivalent to a discount rate of 2 percent per year.

In computing the transition probabilities $P_{a}^{i, j}$, we follow Elsby, Hobijn, and Şahin (2015) to remove possible spurious transitions between the unemployment and out-of-the-laborforce states. For example, if a worker is out of labor force in the first and third months but unemployed in the second month of the survey, we treat the worker as out of the labor force for all three months. The case of a worker who is unemployed in the first and the third months but out of the labor force in the second month is similar: We consider the worker unemployed for all three months. 


\section{NOTES}

1 We drop those who usually work for less than 8 hours per week while employed.

$\underline{2}$ We again drop those who usually work for less than 8 hours per week.

$\underline{3}$ By comparison, the more commonly cited Gini coefficient is for household income, which was roughly 0.47 in the United States over the sample period. The numbers are different for two reasons. First, our unit of observation is individuals, not households. With assortative mating, the Gini coefficient would be higher for households. Second, and more important, capital income is much more unequally distributed than labor (wage) income.

4 In the previous exercise, we assumed that everyone with the same occupation category earned the same wage, regardless of their age.

$\underline{5}$ The PDV at 25 of the cross-sectional Lorenz curve is difficult to construct because the panel dimension of our data is too short for an estimation of lifetime earnings.

6 Occupation categories that have high EN tend to have more younger workers and also more women, although the correlation is fairly weak.

$\underline{7}$ Worker churning means those hires that replace separations from an employer, or the difference between worker flows and job flows at the employer level (Burgess, Lane, and Stevens, 2000). In the firm dynamics literature, churning is the sum of the number of jobs created and the number of jobs destroyed across firms or establishments in a sector or the whole economy (see, for example, Davis, Haltiwanger, and Schuh, 1996). Our notion of gross flows is defined at the occupation level to measure the turnover rate of an occupation.

$\underline{8}$ The lone exception is the building and grounds cleaning occupation category, in which women with a bachelor's degree have a slightly lower average wage than men with less education.

9 In one occupation category, community and social service, the gender gap is virtually nonexistent.

10 Lee, Shin, and Lee (2015) find that for more than 95 percent of the population in the National Longitudinal Survey of Youth, their educational attainment is finalized by 25 years of age.

11 Aum, Lee, and Shin (2017) use a different dataset without panel dimensions to study the changes in employment across occupations during and after the Great Recession.

\section{REFERENCES}

Acemoglu, Daron and Autor, David. "Skills, Tasks and Technologies: Implications for Employment and Earnings," in D. Card and O. Ashenfelter, eds., Handbook of Labor Economics. Volume 4, Part B. Elselvier, 2011, pp. 1043-71; https://doi.org/10.1016/S0169-7218(11)02410-5.

Aum, Sangmin; Lee, Sang Yoon (Tim) and Shin, Yongseok. "Industrial and Occupational Employment Changes During the Great Recession." Federal Reserve Bank of St. Louis Review, First Quarter 2017, 99(4), pp. 307-17; https://doi.org/10.20955/r.2017.307-317.

Burgess, Simon; Lane, Julia and Stevens, David. "Job Flows, Worker Flows, and Churning." Journal of Labor Economics, 2000, 18(3), pp. 473-502; https://doi.org/10.1086/209967.

Davis, Steven J.; Haltiwanger, John C. and Schuh, Scott. Job Creation and Destruction. MIT Press, 1996.

Elsby, Michael W.L.; Hobijn, Bart and Şahin, Ayşegül. "On the Importance of the Participation Margin for Labor Market Fluctuations." Journal of Monetary Economics, 2015, 72, pp. 64-82; https://doi.org/10.1016/j.jmoneco.2015.01.004.

Lee, Sang Yoon (Tim) and Shin, Yongseok. "Horizontal and Vertical Polarization: Task-Specific Technological Change in a Multi-Sector Economy." NBER Working Paper No. 23283, National Bureau of Economic Research, 2017; https://doi.org/10.3386/w23283.

Lee, Sang Yoon (Tim); Shin, Yongseok and Lee, Donghoon. "The Option Value of Human Capital: Higher Education and Wage Inequality." NBER Working Paper No. 21724, National Bureau of Economic Research, 2015; https://doi.org/10.3386/w21724. 


\section{Shin and Yuen}

Nekarda, Christopher J. "A Longitudinal Analysis of the Current Population Survey: Assessing the Cyclical Bias of Geographic Mobility." Working paper, Board of Governors of the Federal Reserve System, 2009; https://chrisnekarda.com/papers/lpd-geomob 20090527.pdf.

Sanders, Carl and Taber, Christopher. "Life-Cycle Wage Growth and Heterogeneous Human Capital." Annual Review of Economics, 2012, 4, pp. 399-425; https://doi.org/10.1146/annurev-economics-080511-111011. 